www.jmscr.igmpublication.org

Impact Factor 5.84

Index Copernicus Value: 83.27

ISSN (e)-2347-176x ISSN (p) 2455-0450

crossref DOI: _https://dx.doi.org/10.18535/jmscr/v5i7.132

Journal Of Medical Science And Clinical Research

\title{
Comparative Study of Transverse Strength and Water Sorption between Conventional and Fiber Reinforced Denture Base Resins - An in Vitro Study
}

\author{
Authors \\ Dr Durga Bhavani Kanaparthi, Dr Atluri Kaleswara Rao, \\ Dr Tripuraneni Sunil Chandra \\ Drs. SNDC Dental, College
}

\begin{abstract}
Background \& Objectives: The purpose of this study is to compare and evaluate the transverse strength and water sorption of conventional and high impact strength denture base resins with the same reinforced with glass fibers.

Materials and Methods: Three hundred and sixty identical samples of dimensions $65 \times 10 \times 3.3 \mathrm{~mm}$ were fabricated from three materials (Group I - DPI, Group II - TREVALON HI and Group III - LUCITONE 199) according to ADA / ANSI Specification No. 12. Each group is divided into two subgroups A and B. 180 specimens were prepared for transverse strength and 180 specimens were prepared for water sorption. These 180 specimens were divided into 30 specimens for each subgroup A and B in three groups.

The standard three point bend test was carried out in Universal Testing Machine at a cross head speed of $1 \mathrm{~mm} / \mathrm{min}$ to evaluate the transverse strength.

For the evaluation of water sorption, the specimens were placed in a desiccator before weighing until a constant mass was reached. The dried specimens were immersed in artificial saliva and placed in an incubator at a temperature of $37^{\circ} \mathrm{c} \pm 1^{\circ} \mathrm{c}$. The specimens were weighed on Electronic weighing balance.

The mean values of transverse strength and water sorption of each material were calculated and the data was analysed using One way ANOVA, TUKEY and t- tests (0.05).

Results: The highest mean transverse strength was found for high impact strength resins reinforced with glass fibers and the lowest mean transverse strength was found for conventional and high impact strength denture base resin materials. The highest mean water sorption was found for conventional denture base resin material and the lowest mean water sorption was found for high impact strength resins reinforced with glass fibers.

Interpretations \& Conclusions Conventional and high impact strength resins reinforced with glass fibers exhibited greater transverse strength values than the unreinforced resin materials compared in this study. Conventional and high impact strength denture base resin materials exhibited greater water sorption values than the same reinforced with glass fibers.

Keywords: Conventional denture base resin, High impact strength resins, Glass fibers.
\end{abstract}

\section{INTRODUCTION}

Polymethyl methacrylate currently is the material of choice for denture base fabrication. Introduced in 1937 by Dr. Walter Wright. In the past, various materials were used for dentures but with less success. Polymethyl methacrylate has been the 
denture base material for more than 60 years and it shows no signs of being replaced. PMMA continues to be used because of its working characteristics, ease of processing, accurate fit, stability in oral environment, superior esthetics, use with inexpensive equipments and adequate mechanical properties. ${ }^{1}$

Most fractures of the denture occur inside the mouth during function, primarily because of resin fatigue. ${ }^{2}$ The denture base resin is subjected to various stresses during function; these include compressive, tensile and shear stresses.

To overcome these short comings, experiments with alternate polymers were conducted, but the polymers failed to produce dentures of great accuracy. To improve the existing material, PMMA modifications have been made. These modifications include chemical modification and mechanical reinforcement through the inclusion of fibers such as glass, aramid, nylon, carbon, stainless steel mesh and polyethylene fibers. ${ }^{1}$

Carbon fibers can be added to PMMA as loose strands or in woven mat form. Dry fibers are difficult to handle but the fibers can be wetted with monomer to form tows of wet fiber which have improved handling characteristics. The inclusion of metals as a mean of reinforcement of PMMA has limited value because the areas of stress concentration outweigh the benefits. ${ }^{4}$ Nylon fibers are polyamide and are based primarily on aliphatic chains. Polyethylene, a naturally crystalline polymer is drawn at temperatures below its melting point, to produce a material of enhanced modulus in the axial direction. Water sorption also affects other physiochemical and mechanical properties such as the hardness, young's modulus, transverse strength and fatigue limit. Water sorption can also influence the dimensional stability.

According to International Standards Organization (ISO) Specification No. 1567, water sorption should not exceed $32 \mu \mathrm{g} / \mathrm{mm}^{3}$ for heat cured or chemical cured materials. For each $1 \%$ increase in weight produced by water absorption, acrylic resin expands $0.23 \%$ linearly. $^{3}$

\section{MATERIALS \&METHODS}

The denture base resin materials used in this study were DPI (conventional), Trevalon HI (high impact strength) and Lucitone 199 (high impact strength).

A total of 360 specimens were prepared from three different materials of which,

- 60 specimens were prepared for Group I, sub group A (DPI, Conventional)

- 60 specimens were prepared for Group I sub group B (DPI, Glass fiber reinforced)

- 60 specimens were prepared for Group II, sub group A (Trevalon HI, conventional)

- 60 specimens were prepared for Group II, sub group B (Trevalon HI, Glass fiber reinforced)

- 60 specimens were prepared for Group III, sub group A (Lucitone 199, Conventional)

- 60 specimens were prepared for Group III, sub group B (Lucitone 199, Glass fiber reinforced)

For testing Transverse strength: All the prepared 90 specimens were stored in water at room temperature for 1 week before testing. The specimens were removed from water after 1 week and allowed to remain in air at room temperature for atleast 24 hours before testing and then were subjected to 3-point bending test.

For evaluation of Water sorption: All the prepared 90 specimens were stored in artificial saliva.

The load at which fracture occurred was noted and converted to Transverse strength (TS) by using the following formula:

$\mathrm{TS}=(3 \mathrm{PL}) /\left(2 \mathrm{bd}^{2}\right)$

Where, $\mathrm{TS}=$ Transverse strength $(\mathrm{MPa})$,

$\mathrm{P}=$ Fracture load $(\mathrm{N}), \mathrm{L}=$ Length between the jig tips, $50 \mathrm{~mm}, \mathrm{~b}=$ Specimen width, $10 \mathrm{~mm}, \mathrm{~d}=$ Specimen thickness, $3.3 \mathrm{~mm}$

By substituting the above formula for each load value obtained, the transverse strength was calculated for all 180 specimens. The transverse strength value obtained was in Mega Pascal (Mpa). 


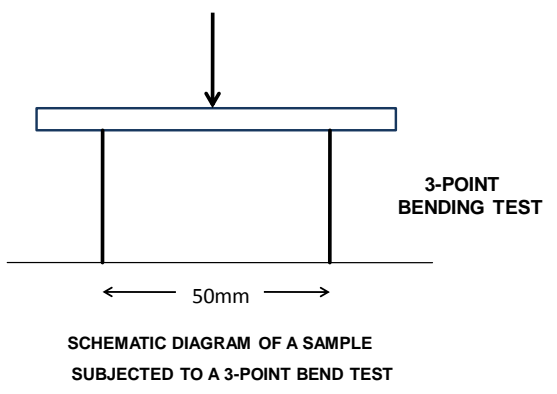

The Water sorption (WS) was calculated by using the formula:

$\mathrm{WS}=\left(\mathrm{m}_{6}-\mathrm{m}_{1}\right) / \mathrm{V}$

Where, WS $=$ Water sorption $\left(\mu \mathrm{g} / \mathrm{mm}^{3}\right), \mathrm{m}_{6}=$ Weight of the specimen after 28 days in artificial saliva $(\mu \mathrm{g}), \mathrm{m}_{1}=$ Weight of the specimen before placement in artificial saliva $(\mu \mathrm{g}), \mathrm{V}=$ Volume of the specimen $\left(\mathrm{mm}^{3}\right)$

The mean values and standard deviation of transverse strength and water sorption of data obtained from various groups were calculated.

\section{OBSERVATIONS \& RESULTS}

Analysis of mean values of transverse strength (in $\mathrm{MPa}$ among conventional and high impact strength resins and among conventional and high impact strength resins reinforced with glass fibers was done by One way ANOVA test, revealed that within the limitations of the study, there was highly significant difference in the mean transverse strength among the groups $(\mathrm{p}<0.01)$.

Analysis of mean values of transverse strength (in $\mathrm{MPa}$ ) between conventional and high impact strength resins and between conventional and high impact strength resins reinforced with glass fibers was done by TUKEY test, revealed that within the limitations of the present study, there was highly significant difference in transverse strength values between DPI - TRAVALON HI and TREVALON HI - LUCITONE 199 ( $p<0.01)$. The statistical analysis revealed that there is no significant difference between the transverse strength values of DPI - LUCITONE 199 $(\mathrm{p}=0.34)$.

Analysis of mean values of water sorption (in $\mu \mathrm{g} / \mathrm{mm}^{3}$ ) among conventional and high impact strength resins and among conventional and high impact strength resins reinforced with glass fibers was done by One way ANOVA test, revealed that within the limitations of the present study, there was highly significant difference in the mean water sorption among the groups $(\mathrm{p}<0.01)$.

Analysis of mean values of water sorption (in $\mu \mathrm{g} / \mathrm{mm}^{3}$ ) between conventional and high impact strength resins and between conventional and high impact strength resins reinforced with glass fibers was done by TUKEY test, revealed that within the limitations of the present study, there was highly significant difference in water sorption values among groups $(\mathrm{p}<0.01)$.

TABLE 1: Comparison of Mean Between Groups (Conventional and High Impact Strength Resins and Conventional and High Impact Strength Resins Reinforced With Glass Fibers) in Transverse Strength by Using T- Test

\begin{tabular}{|c|c|c|c|c|c|}
\hline Groups & Parameters & Mean & t-value & P-value & Inference \\
\hline \multirow{2}{*}{ DPI } & $\begin{array}{l}\text { Reinforced } \\
\text { glass fibers }\end{array}$ & 146.98 & \multirow{2}{*}{15.511} & \multirow{2}{*}{$<0.01$} & \multirow{2}{*}{$\begin{array}{l}\text { HIGHLY } \\
\text { SIGNIFICANT }\end{array}$} \\
\hline & Conventional group & 98.51 & & & \\
\hline \multirow{2}{*}{ TREVALON HI } & 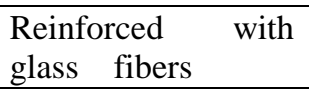 & 158.00 & \multirow{2}{*}{17.810} & \multirow{2}{*}{$<0.01$} & \multirow{2}{*}{$\begin{array}{l}\text { HIGHLY } \\
\text { SIGNIFICANT }\end{array}$} \\
\hline & $\begin{array}{l}\text { High impact } \\
\text { strength resin group }\end{array}$ & 110.87 & & & \\
\hline \multirow{2}{*}{ LUCITONE 199} & 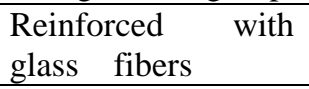 & 149.17 & \multirow{2}{*}{17.423} & \multirow{2}{*}{$<0.01$} & \multirow{2}{*}{$\begin{array}{l}\text { HIGHLY } \\
\text { SIGNIFICANT }\end{array}$} \\
\hline & $\begin{array}{l}\text { High impact } \\
\text { strength resin group }\end{array}$ & 101.81 & & & \\
\hline
\end{tabular}


TABLE 2: Comparison of Mean Between Groups (Conventional and High Impact Strength Resins and Conventional and High Impact Strength Resins Reinforced with Glass Fibers) in Water Sorption by Using T- Test

\begin{tabular}{|c|c|c|c|c|c|}
\hline Groups & Parameters & Mean & t-value & P-value & Inference \\
\hline \multirow{2}{*}{ DPI } & Reinforced with glass fibers & 27.70 & \multirow{2}{*}{-2.203} & \multirow{2}{*}{$<0.01$} & \multirow{2}{*}{$\begin{array}{c}\text { HIGHLY } \\
\text { SIGNIFICANT }\end{array}$} \\
\hline & Conventional group & 28.51 & & & \\
\hline \multirow{2}{*}{ TREVALON HI } & Reinforced with glass fibers & 14.54 & \multirow{2}{*}{-2.871} & \multirow{2}{*}{$<0.01$} & \multirow{2}{*}{$\begin{array}{c}\text { HIGHLY } \\
\text { SIGNIFICANT }\end{array}$} \\
\hline & High impact strength resin group & 15.37 & & & \\
\hline \multirow{2}{*}{ LUCITONE 199} & Reinforced with glass fibers & 20.32 & \multirow{2}{*}{-2.207} & \multirow{2}{*}{$<0.01$} & \multirow{2}{*}{$\begin{array}{c}\text { HIGHLY } \\
\text { SIGNIFICANT }\end{array}$} \\
\hline & High impact strength resin group & 21.09 & & & \\
\hline
\end{tabular}

\section{DISCUSSION}

Transverse strength, flexural strength or modulus of rupture is essentially a strength test of a bar supported at each end, or a thin disk supported along a lower support circle, under a static load. The flexural strength of a material is a combination of compressive, tensile and shear strengths. As the tensile and compressive strengths increase, the force required to fracture the material also increases. Compared with conventional polymer materials, fiber reinforced polymers are successful in their application primarily because of their high specific modulus and specific strength. ${ }^{4}$

Water sorption can be reduced by decreasing the polymer content which attracts water by polarization. A filler material can full fill this which functions in dual way by reducing the polymer content and improving the mechanical properties. So, a suitable filler reinforcing material is required ${ }^{5}$.

Several studies have been conducted for the evaluation of water sorption in which denture base resin material was reinforced with fibers in different forms. ${ }^{5}$ Also studies were done to evaluate the water sorption by reinforcing the heat cured and chemical cured denture base resins with fibers. ${ }^{3}$

The standard three point bend test was carried out in Universal Testing Machine (MODEL 34482) at a cross head speed of $1 \mathrm{~mm} / \mathrm{min}$ with a load of
$250 \mathrm{~kg}$ applied at the center of the specimen to evaluate the transverse strength. The specimens were placed on the jigs which are $50 \mathrm{~mm}$ apart from each other. Each specimen was gradually loaded and the point it flexes and breaks was noted. This is the load required to break the specimen and was obtained in Newton with the help of the analysis software. The transverse strength value obtained was in Mega Pascal (Mpa).

The results obtained for transverse strength were in accordance with the previous study conducted by Jacob John, Gangadhar and Illa Shah ${ }^{1}$ that the reinforcement of the denture base resin with glass, aramid or nylon fibers improved the flexural strength of the resin and also in accordance with the previous study conducted by Dagar, Pakhan, Thombare and Motwani ${ }^{6}$ that the reinforcement of the denture base resin with either glass or nylon fibers improve the mechanical properties of resin. For the evaluation of water sorption, the specimens were placed in a desiccator before weighing until a constant mass was reached. The dried specimens were immersed in artificial saliva and placed in an incubator at a temperature of $37^{\circ} \mathrm{c} \pm 1^{\circ} \mathrm{c}$. The specimens were weighed on Electronic weighing balance. The weighing procedure was repeated on days $0\left(\mathrm{~m}_{1}\right), 1\left(\mathrm{~m}_{2}\right), 7$ $\left(\mathrm{m}_{3}\right), 14\left(\mathrm{~m}_{4}\right), 21\left(\mathrm{~m}_{5}\right)$ and $28\left(\mathrm{~m}_{6}\right)$. 
According to ISO 1567, the increase in volumetric mass of the denture base material per unit volume (Water sorption) should not exceed $32 \mu \mathrm{g} / \mathrm{mm}^{3}$.

The results obtained for water sorption were in accordance with the International Standards Organization (ISO) Specification No. 1567, water sorption should not exceed $32 \mu \mathrm{g} / \mathrm{mm}^{3}$ for heat cured or chemical cured materials. ${ }^{6}$ Also the results obtained were in accordance with the previous study conducted by Cal et $\mathrm{al}^{26}$ that the polymerization shrinkage and water sorption of denture base polymers is lower when the specimens are reinforced with glass fibers and also the water sorption values were decreased significantly as the glass fiber content increased. In the present study, the glass fiber content is not increased and a consistent amount of glass fiber ( $2 \%$ by weight) was used and it was found that the water sorption of conventional and high impact strength denture base resins reinforced with glass fibers was lower than the conventional and high impact strength denture base resins.

The results of the present study matched consistently with those found in other studies with a similar design. From this study, it was observed that reinforcement of conventional and high impact strength resins with glass fibers improves the transverse strength and decreases the water sorption.

Different types of fibers like Glass, Aramid, Nylon, Polyethylene, Carbon and Kevlar are available and among these fibers, glass fibers are commonly available. Previous studies ${ }^{1,7}$ have shown that glass reinforced specimens exhibited better transverse strength than the specimen groups reinforced with other fibers. In the present study, glass fibers have been chosen for the reinforcement of conventional and high impact strength denture base resins. Glass fiber reinforced dentures are much stronger and more resilient under flexural fatigue or impact stress conditions and also absorbs less water content than conventional and high impact strength resin dentures and hence the chances of fracture of the denture can be substantially eliminated ${ }^{1}$.

\section{CONCLUSION}

The results of this study lead to the following conclusions:

1) On comparing the transverse strength between conventional and high impact strength denture base resins with conventional and high impact strength denture base resins reinforced with glass fibers, it was found that the specimens of conventional and high impact strength resins reinforced with glass fibers were more resistant to flexural fatigue than conventional and high impact strength resins.

2) On comparing the water sorption between conventional and high impact strength denture base resins with conventional and high impact strength denture base resins reinforced with glass fibers, it was found that the conventional and high impact strength denture base resins reinforced with glass fibers exhibited lower water sorption than conventional and high impact strength denture base resins.

\section{ACKNOWLEDGMENTS}

It is with privilege and honour that I take this opportunity to express my sincere and heartfelt thanks to my guideDr. A. KALESWARA RAO, Professor and Head, Department of Prosthodontics and Crown \& Bridge, Drs.Sudha\&Nageswara Rao Siddhartha Institute of Dental Sciences, whose enthusiasm, kind advice, unfailing support helped me to bring this dissertation to a successful completion.

Gratitude is an inadequate word for Dr, T. SUNIL CHANDRA,Professorfor his endless contribution of time along with ceaseless constant inspiration and for the valuable suggestions rendered during the course of the study.

\section{REFERENCES}

1. John, Gangadhar and Shah. Flexural strength of heat polymerized poly methyl methacrylate denture resin reinforced with glass, aramid or nylon fibers. J Prosthet Dent 2001;86:424-7. 
2. Smith DC. Recent developments and prospects in dental polymers. J Prosthet Dent 1962;12:1066-78.

3. Miettinen and Vallittu. Water sorption and solubility of glass fiber reinforced denture poly methyl methacrylate resin. J Prosthet Dent 1996;76:531-4.

4. Anusavice KJ. Phillip's Science of Dental Materials. 11 ed: Elsevier Science; 2003.

5. Cal et al. Water sorption and dimensional changes of denture base polymer reinforced with glass fibers in continuous unidirectional and woven form, Int $\mathrm{J}$ Prosthodont 2000;13:487-93.

6. Dagar, Pakhan, Thombare and Motwani. The evaluation of flexural strength and impact strength of heat polymerized poly methyl methacrylate denture base resin reinforced with glass and nylon fibers: An In Vitro study. J Indian ProsthodontSoc 2008;8:98-104.

7. Solnit. The effect of methyl mathacrylate reinforcement with silane treated and untreated glass fibers. J Prosthet Dent 1991;66:310-4. 